\title{
Wear Problem
}

National Cancer Institute

\section{Source}

National Cancer Institute. Wear Problem. NCI Thesaurus. Code C92130.

Problems due to the premature or expected erosion of its material by use, deterioration, or change. 